Theory of Groundwater Flow 
Macmillan Civil Engineering Hydraulics Series

General Editor: E. M. Wilson, $\mathrm{PhD}$, MSc, FICE

Reader in Civil Engineering, University of Salford

Flow IN ChaNNELS: $R$. J. $H$. Sellin

ENGINEERING HYDROLOGY: E. M. Wilson

COASTAL HYDRAULICS: $A$. M. Muir Wood

ANALYSiS OF SURGE: John Pickford 


\title{
Theory of Groundwater Flow
}

\author{
A. Verruijt
}

Delft University of Technology

The Netherlands 
(C) A. Verruijt 1970

Softcover reprint of the hardcover 1st edition 1970

All rights reserved. No part of this publication may be reproduced or transmitted, in any form or by any means, without permission.

First published 1970

Published by

MACMILLAN AND CO LTD

London and Basingstoke Associated companies in New York, Toronto

Dublin, Melbourne, Johannesburg and Madras

ISBN 978-1-349-00177-4 ISBN 978-1-349-00175-0 (eBook)

DOI 10.1007/978-1-349-00175-0 


\section{Preface}

The aim of this book is to present the fundamentals of the theory of groundwater flow, and the most effective methods for solving groundwater flow problems occurring in civil engineering practice. Technical and practical aspects are not discussed. These will be treated in a companion volume, Groundwater Recovery and Recharge, by Professor L. Huisman.

Although the book is in principle intended to be an introductory text, I have not been able to withstand the temptation to include some theoretically rather complicated methods, notably the complex variable method and the finite element method. These are treated in chapters 7, 8 and 10, which may be omitted without impeding the understanding of the remaining parts of the book. Yet I hope that some readers will be attracted by the charm of the complex variable method, or by the power of the finite element method. This latter method has been developed in recent years, mainly for computer calculations, and will certainly become more and more important in the near future, especially when general programmes become available.

None of the methods presented in this book, and practically none of the examples, have been developed by me. Some care has been taken to mention the original sources. In addition to these references, however, I wish to express my personal indebtedness to all those who have contributed to the development of the theory of groundwater flow in the Netherlands, and who can probably best be thanked collectively in the group of engineers together constituting the 'Hydrologic Colloquium'. 
I am particularly indebted to Professor G. de Josselin de Jong, who taught me mechanics, and who made me see the power and the beauty of various mathematical techniques for solving engineering problems.

I have much profited from the comments of Dr E. M. Wilson, the editor of this series, on the manuscript in its first stage. Finally I want to thank my sister Alice for producing most of the typescript.

DELFT, The Netherlands

A.V.

May 1969 


\section{Contents}

1 Introduction 1

1.1 Properties of soils 2

1.2 Properties of water 2

References 4

2 Darcy's law 6

2.1 Darcy's experiment 6

2.2 Intrinsic permeability 9

2.3 Viscous character of groundwater flow 10 Problems $\quad 12$

References 13

3 Fundamental equations of groundwater flow 14

3.1 Generalization of Darcy's law 14

3.2 Equation of continuity 21

Problems $\quad 23$

References 24 
4 Elementary problems for confined or semi-confined aquifers

4.1 Basic equation 26

4.2 Rectilinear flow 29

4.3 Differential equation for radial flow 34

4.4 Radial flow in a completely confined aquifer 35

4.5 Radial flow in a semi-confined aquifer 39

Problems $\quad 46$

References $\quad 47$

5 Elementary problems for unconfined aquifers

5.1 The Dupuit-Forchheimer assumption 48

5.2 One-dimensional problems 51

5.3 Radial flow 54

Problems $\quad 56$

References $\quad 57$

6 General aspects of two-dimensional problems

6.1 Superposition $\quad 58$

6.2 Method of images 66

6.3 Potential and stream function 72

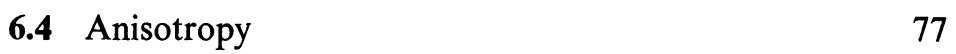

6.5 Discontinuous permeability 80

Problems $\quad 83$

References $\quad 85$

7 Functions of a complex variable $\quad 86$

7.1 The algebra of complex numbers 86

7.2 Analytic functions of a complex variable 90 
7.3 Conformal transformations 98

7.4 The Schwarz-Christoffel transformation 102 Problems $\quad 106$

$\begin{array}{ll}\text { References } & 107\end{array}$

8 Complex variable techniques 108

8.1 Simple boundary-value problems 108

$\begin{array}{ll}\text { 8.2 Free surface flow } & 119\end{array}$

8.3 The hodograph method 128

8.4 The Zhukovsky function 133

8.5 Interface problems 136

Problems $\quad 142$

References $\quad 142$

9 Approximate methods $\quad 144$

9.1 Graphical method 144

9.2 Relaxation method 149

9.3 Method of fragments 155

Problems $\quad 158$

References $\quad 158$

10 The finite element method 159

10.1 Variational formulation of the fundamental problem 159

$\begin{array}{ll}10.2 & \text { Finite elements } \\ 10.3 & \end{array}$

10.3 Steady flow with a free surface 167

10.4 Non-steady flow with a free surface 170

References $\quad 173$

11 Analogue methods 174

$\begin{array}{ll}\text { 11.1 Electric analogue } & 175\end{array}$

11.2 Hele Shaw analogue 179

References 182 
Contents

Appendix: Bessel functions

Notations

Conversion factors

188

Index 